\title{
Birmingham Medical Research Expeditionary Society 1977 Expedition: Cardiopulmonary function before, during and after a twenty-one-day Himalayan trek
}

\author{
R. A. StOCKLEY* \\ M.D., M.R.C.P. \\ I. D. GREEN $\dagger$ \\ Ph.D., F.R.C.P. \\ *Department of Medicine, University of Birmingham, Queen Elizabeth Hospital and \\ †Selly Oak Hospital, Birmingham
}

\begin{abstract}
Summary
The heart rate response to exercise was studied in 17 normal subjects before, during and after a 21-day Himalayan trek to $5490 \mathrm{~m}$. The group were fitter before the trek when compared to normal subjects of a similar age $(P<0.001)$ having a lower heart rate response to exercise for their lean body mass. The trek significantly increased the 'fitness' of the group as a whole $(P<0.025)$ but this was not seen in the 5 members of the group who had severe acute mountain sickness. Similar changes were noted within the first 8 days of the trek before symptoms of mountain sickness occurred.

The group had normal pulmonary function before the trek but peak expiratory flow rate and vital capacity decreased with altitude. The effect was more marked in the subjects with acute mountain sickness.
\end{abstract}

\section{Introduction}

The aetiology of acute mountain sickness (AMS) is largely unknown but certainly the physiological acclimatization to altitude involves substantial changes in the cardiovascular and respiratory systems. Hackett, Rennie and Levine (1976) found that AMS occurred more commonly in subjects who ascended rapidly and thus had less time to acclimatize and Singh et al. (1969) found both bradycardia and a fall in peak expiratory flow rate (PEFR) in affected subjects. The purpose of the present study was to measure cardio-respiratory function before, during and after a Himalayan trek (Fletcher, 1979) in order to assess its effect upon 'fitness' and in particular to investigate the use of simple tests of cardio-respiratory function for predicting the occurrence of AMS.

\section{Methods}

Seventeen male subjects aged 23-50 years were studied. None had any history of cardiorespiratory disease and only 2 smoked regularly.

\section{Baseline data}

Before the trek all subjects underwent a variety of cardiorespiratory investigations. A progressive submaximal exercise test was performed on a cycle ergometer as described by Spiro et al. (1974). Cardiac frequency was recorded using a Cardiopan ECG machine and inspired ventilation from a Tissot spirometer. The expired gas was passed through a 6-litre mixing chamber and its composition analysed by a paramagnetic oxygen analyser (Servomex) and infra-red carbon dioxide analyser (Godart capnograph). Oxygen uptake was calculated from inspired ventilation and expired gas composition measurements after applying a nitrogen correction (Cotes, 1975). Fitness was assessed using the method of Spiro et al. (1974) from the progressive exercise test and using the formula of Astrand (1960) to predict maximum cardiac frequency.

$$
\text { Fitness }=\frac{\text { SFH }}{\mathrm{ACFH}} \times \text { LBM }
$$

where: $\mathrm{SFH}=$ heart rate increase per litre of oxygen uptake

$\mathrm{ACFH}=$ adaptation capacity for heart rate (predicted maximum minus resting value)

$$
\text { LBM }=\text { lean body mass }
$$

The lower the value for Fitness index the 'fitter' the subject.

Lean body mass was obtained by subtracting the total body fat, estimated using Harpenden Calipers (Fletcher, 1962) from total body weight.

Lung volumes were measured by conventional spirometry, total lung capacity using the helium dilution method and transfer factor for carbon monoxide using the single breath method. Dynamic flow rates were measured from the integrated output of a Fleisch pneumotachograph.

\section{During the trek}

Heart rate was recorded on waking before the subjects rose. During the lunch stop, resting heart rate was recorded and the subjects performed a simple exercise test. This consisted of running on the spot raising the thighs horizontally 20 times. Heart rate was recorded at the end of the exercise and at 
30-sec intervals for a further 2 min. PEFR was recorded as the best of 3 attempts using a Wright's peak flow meter, and vital capacity using a Wright anemometer.

\section{After the trek}

The progressive submaximal exercise test and lean body mass measurements were repeated in all subjects within 3 days of the return from Nepal.

The association of our results with AMS was assessed using the peer review data (Fletcher, 1979). The results of the 5 worst, 5 least affected subjects and the group as a whole were compared using Student's $t$-test.

\section{Results}

\section{Before and after the trek}

None of the subjects had any clinical or physiological evidence of cardiopulmonary disease. Pulmonary function was normal for each subject predicted for age and height (Cotes, 1975) and showed no correlation with the subsequent development of AMS.

Submaximal exercise test. The results of the submaximal exercise test for the group as a whole on selected days are given in Table 1 together with the lean body mass.

There was no correlation between any of the measurements of submaximal exercise before the trek and the subsequent development of AMS.

The data obtained from the submaximal exercise test on return from the trek showed a significant decrease in heart rate at all levels of oxygen uptake in the group as a whole (Table 1). There was no change in lean body mass but the group was 'fitter' $(P<0.025)$ demonstrating an overall training effect of the trek.

TABLE 1. The heart rate response to progressive exercise before and after the trek. The mean value is given for the submaximal indices recommended by Cotes (1972). The slope of the heart rate against oxygen uptake is shown together with lean body mass, 'fitness' and the significance of any change. Figures in parentheses are \pm s.e. mean.

\begin{tabular}{lccc}
\hline Seventeen subjects & Before & After & $P$ \\
\hline Heart rate $(0.75)$ & 95.2 & 90.8 & $<0.05$ \\
& $(3.0)$ & $(2.9)$ & \\
Heart rate $(1.0)$ & 104.8 & 99.6 & $<0.025$ \\
& $(3.1)$ & $(3.0)$ & \\
Heart rate $(1 \cdot 5)$ & 123.9 & 117.4 & $<0.01$ \\
& $(3.6)$ & $(3.1)$ & \\
Slope & 38.3 & 35.5 & n.s. \\
(heart rate/litre oxygen uptake) & $(2.4)$ & $(1.7)$ & \\
Lean body mass (kg) & 55.9 & 56.0 & n.s. \\
& $(1.6)$ & $(1.5)$ & \\
'Fitness' & 19.61 & 17.87 & $<0.025$ \\
& $(0.97)$ & $(0.59)$ & \\
\hline
\end{tabular}

(Figures in parentheses after heart rate indicate oxygen uptake in litre/min).

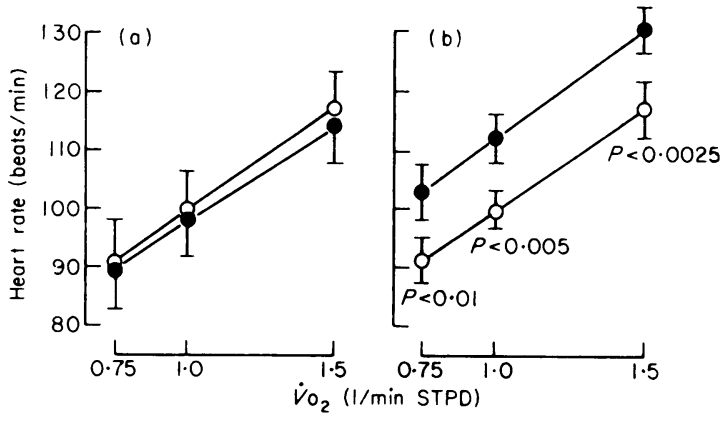

FIG. 1. Results of the progressive submaximal exercise test before (O) and after (O) the trek. (a) Five subjects most affected by AMS and (b) 5 subjects least affected. The vertical axes are heart rate in beats/min and horizontal axes are oxygen uptake (Voz) with values at submaximal indices $(0.75,1.0$ and 1.5 litres/min oxygen uptake) suggested by Cotes (1972). Standard error bar lines are shown and the significance of any difference is given. STPD = standard temperature and pressure, dry, i.e. $0^{\circ} \mathrm{C} 760 \mathrm{mmHg}$.

The 5 subjects who had severe symptoms of AMS did not show this decrease in heart rate response to exercise following the trek (Fig. 1). Furthermore there was no increase in their 'fitness' [mean value before the trek, 17.06 (s.e. \pm 1.55$)$; mean value after the trek, 18.21 (s.e. \pm 0.98$) ; P>0 \cdot 1]$. On the other hand the 5 subjects least affected by symptoms of AMS showed a significant decrease in their heart rate response to exercise following the trek (Fig. 1). Furthermore, these 5 subjects also become 'fitter' [mean value before the trek, 19.47 (s.e. \pm 1.25 ); mean value after the trek, 16.55 (s.e. \pm 0.97 ); $P<0.01]$.

However, despite these changes within each group it was not possible to separate them statistically either before or after the trip because of the small numbers and large range in each group.

\section{During the trek}

Waking, resting and exercise heart rate. During the first 7 days of the trek there was very little difference between the mean heart rates although the tendency was for the values to fall [waking, 62.5 (s.e. $\pm 2 \cdot 5$ ) to 62.0 (s.e. \pm 2.0 ); resting, 87.5 (s.e. \pm 3.4 ) to 75.1 (s.e. \pm 2.5 ); exercise, 133.4 (s.e. \pm 3.2 ) to $124 \cdot 8$ (s.e. $\pm 2 \cdot 6)]$.

From the eighth day the group climbed to and remained above $3100 \mathrm{~m}$. Thereafter a positive correlation was found between waking, resting and exercise pulse rates and altitude $(P<0.025 ;<0.001$; $<0.001$ respectively). There was no difference between those subjects who developed AMS and those who did not.

The exercise test used during the trek was by necessity simple. However, Table 2 shows the 
TABLE 2. Heart rate response to simple exercise test on consecutive days in one subject. Mean values are given for resting and exercise heart rate as well as 30 -sec intervals after the cessation of exercise. $n=$ number of tests analysed and figures in parentheses are \pm s.d.

\begin{tabular}{lrc}
\hline & $(n=5)$ & $(n=4)$ \\
\hline Rest & $52 \cdot 2(2 \cdot 5)$ & $52 \cdot 3(0 \cdot 5)$ \\
Exercise & $106 \cdot 0(2 \cdot 8)$ & $107 \cdot 0(2 \cdot 0)$ \\
$30 \mathrm{sec}$ & $62 \cdot 0(2 \cdot 8)$ & $59 \cdot 0(2 \cdot 0)$ \\
$60 \mathrm{sec}$ & $53 \cdot 2(1 \cdot 1)$ & $52 \cdot 0(0)$ \\
$90 \mathrm{sec}$ & $49 \cdot 6(2 \cdot 2)$ & $51 \cdot 5(1 \cdot 0)$ \\
$120 \mathrm{sec}$ & $50 \cdot 8(2 \cdot 7)$ & $53 \cdot 0(2 \cdot 0)$ \\
\hline
\end{tabular}

results of repeated exercise tests on consecutive days in one of the subjects (mean value and standard deviation of 5 and 4 tests respectively). Thus, although simple, the test was highly reproducible in an individual.

The results are summarized in Table 3 of the test in the group as a whole on day one of the trek, day 8 (the first above $3100 \mathrm{~m}$ ), day 12 (highest point of study, $5035 \mathrm{~m}$ ) and day 21 (return to Pokhara).

The average resting and exercise pulse rates were lower by day 8 compared to the first day of the trek $(P<0.0025)$. Furthermore, the recovery of resting pulse rate was more rapid after 7 days of trekking, occurring $90 \mathrm{sec}$ after the cessation of exercise compared to $120 \mathrm{sec}$ on the first day. This improvement was maintained by the end of the trek when the group returned to Kathmandu (Fig. 2). As the group climbed above $3100 \mathrm{~m}$ the average pulse rate values rose progressively above those on day $8(P<0.005$ by day 12$)$ although recovery of resting values still occurred earlier than on the first day of the trek.

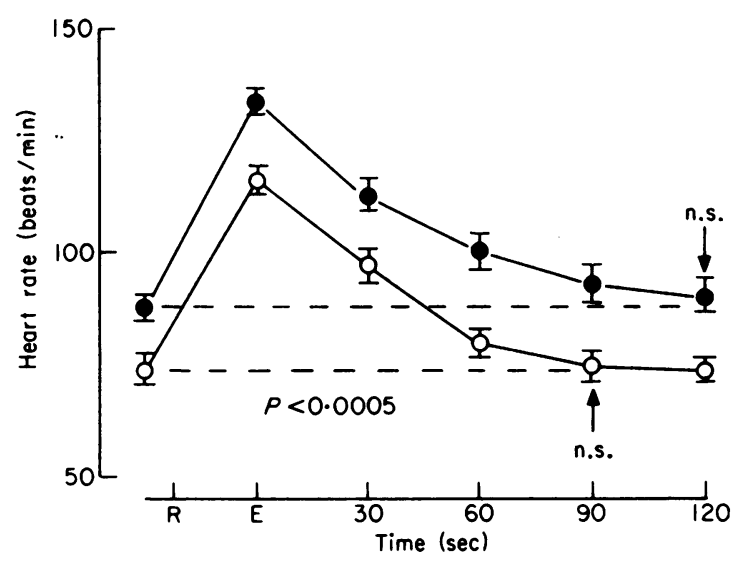

FIG. 2. Results of the simple exercise test on 17 subjects on the first $(O)$ at $1100 \mathrm{~m}$ and last $(O)$ at $1450 \mathrm{~m}$ days of the trek. The vertical axis is heart rate in beats/min and the horizontal axis is the value at rest (R), at the end of exercise (E) and at 30-sec intervals from the cessation of exercise. The return to resting levels is indicated (n.s.). The significance of any difference $(P)$ between the average results for the group is shown together with the standard error bar lines. The horizontal dotted lines are the average resting values for each day.

There was no correlation between the exercise test on trek and the degree of AMS that occurre subsequently. In particular no subjects showed $\vec{a}$ tendency to bradycardia even after the development of symptoms.

However, when the 5 most seriously and 5 least affected individuals were considered separately, the improvement in resting, exercise and recovery pulse rates seen in the group as a whole during the first 8

TABLE 3. Results of the exercise test on 17 subjects on trek. The mean heart rates are given, with s.e. in parentheses, at rest, at the end of exercise and at 30-sec intervals from the cessation of exercise. The days of the trek are shown together with the height above sea level.

\begin{tabular}{|c|c|c|c|c|c|c|c|}
\hline & \multicolumn{7}{|c|}{ Heart rate (beats/min) } \\
\hline & $\begin{array}{c}\text { Height } \\
\text { (m) }\end{array}$ & Rest & Exercise & $30 s$ & $60 \mathrm{~s}$ & $90 \mathrm{~s}$ & $120 \mathrm{~s}$ \\
\hline Day 1 & 1100 & $\begin{array}{l}87 \cdot 5 \\
(3 \cdot 4)\end{array}$ & $\begin{array}{r}133 \cdot 4 \\
(3 \cdot 2)\end{array}$ & $\begin{array}{r}112 \cdot 4 \\
(4 \cdot 1)\end{array}$ & $\begin{array}{r}100 \cdot 0 \\
(4 \cdot 2)\end{array}$ & $\begin{array}{l}92 \cdot 8 \\
(3 \cdot 1)\end{array}$ & $\begin{array}{l}90 \cdot 2^{*} \\
(3 \cdot 4)\end{array}$ \\
\hline Day 8 & 3510 & $\begin{array}{l}75 \cdot 1 \\
(2 \cdot 2)\end{array}$ & $\begin{array}{r}124 \cdot 8 \\
(2 \cdot 6)\end{array}$ & $\begin{array}{r}105 \cdot 5 \\
(3 \cdot 4)\end{array}$ & $\begin{array}{l}79 \cdot 8 \\
(2 \cdot 9)\end{array}$ & $\begin{array}{l}74 \cdot 5^{*} \\
(2 \cdot 7)\end{array}$ & $\begin{array}{l}74 \cdot 6 \\
(2 \cdot 5)\end{array}$ \\
\hline Day 12 & 5035 & $\begin{array}{l}88 \cdot 0 \\
(2 \cdot 9)\end{array}$ & $\begin{array}{r}137 \cdot 5 \\
(2 \cdot 8)\end{array}$ & $\begin{array}{r}117 \cdot 1 \\
(3 \cdot 6)\end{array}$ & $\begin{array}{l}92 \cdot 9 * \\
(4 \cdot 8)\end{array}$ & $\begin{array}{r}83 \cdot 3 \\
(3 \cdot 5)\end{array}$ & $\begin{array}{l}82 \cdot 0 \\
(3 \cdot 3)\end{array}$ \\
\hline Day 21 & 1435 & $\begin{array}{r}73 \cdot 3 \\
(2 \cdot 9)\end{array}$ & $\begin{array}{r}117 \cdot 3 \\
(3 \cdot 6)\end{array}$ & $\begin{array}{r}97.9 \\
(3.9)\end{array}$ & $\begin{array}{c}80.6 \\
(3.6)\end{array}$ & $\begin{array}{l}74 \cdot 2^{*} \\
(2 \cdot 9)\end{array}$ & $\begin{array}{l}73 \cdot 6 \\
(3 \cdot 1)\end{array}$ \\
\hline
\end{tabular}

*indicates when the recovery heart rate is no longer significantly greater than the resting value. 
days was not observed in the 5 subjects who later had most symptoms of AMS (Fig. 3).

Pulmonary function tests. The average PEFR of the group was 591.2 (s.e. \pm 12.7 ) litres/min on the first day of the trek. This remained unaltered until day 8 when the group first climbed above $3100 \mathrm{~m}$. At this point the mean PEFR fell to 563.8 (s.e. \pm 16.0 ) litres/min $(P<0.0025)$. There was no further change in PEFR with altitude although it was not possible to make recordings at the highest camp $(5035 \mathrm{~m})$ because the peak flow meters became frozen. studied on trek with simple tests of lung function in order to correlate the results with AMS and investigate their use as a predictor of AMS. Thirdly, the authors wished to investigate the effects of an arduous 3-week trek on physical 'fitness' as shown by the heart rate response to progressive exercise.

The baseline data showed that none of the subjects had any evidence of cardiopulmonary disease. It is worthy of note that the group as a whole were fitter than a similar group of normal subjects previously studied by Spiro et al. (1974) $(P<0.001$, using

\section{(b)}

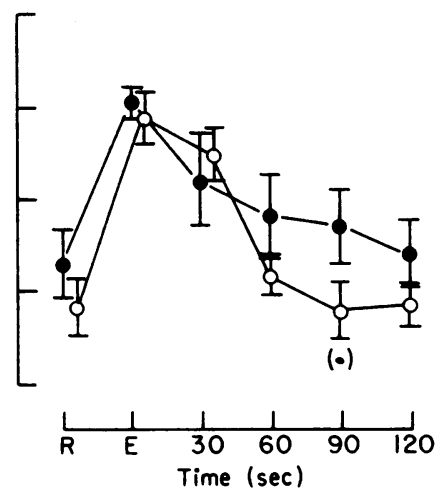

Fig. 3. Results of the simple exercise test on day 1 and day 8. (a) For the 5 subjects least affected by AMS (control) and (b) the 5 subjects most affected by AMS. Standard error bar lines are shown together with the significance of any difference $(P) . \mathrm{R}=$ rest; $\mathrm{E}=$ exercise; day 1 ; $O$ day 8 ; (•) $P<0.001$; (..) $P<0.0025$.

Although the mean level of PEFR fell in the 5 subjects least affected with AMS [577.0 (s.e. $\pm 38 \cdot 5$ ) to 549.0 (s.e. $\pm 46 \cdot 6$ )] this was not statistically significant $(P>0 \cdot 25)$. However in the group severely affected the fall in PEFR [from 609.0 (s.e. $\pm 20 \cdot 6$ ) to 589.0 (s.e. \pm 19.7$)$ ] was significant on day 8 $(P<0.01)$.

The vital capacity showed no change for the first 10 days of the trek (mean value 4.49 litres; s.e. $\pm 0 \cdot 19$ ). The following day, at $4575 \mathrm{~m}$, the vital capacity fell to 4.26 litres, s.e. $\pm 0.19(P<0.0025)$ and again on day 12, at $5035 \mathrm{~m}$, it fell to 3.97 litres, s.e. $\pm 0.19(P<0.0005)$. These changes were seen in the subjects with and in those without AMS.

\section{Discussion}

The purpose of the present investigation was threefold. Firstly, to see if baseline cardiopulmonary function could predict which subjects were most likely to develop severe AMS. Secondly, waking, resting, exercise and recovery pulse rates were standard error of difference of means). This was not a particularly surprising finding since many of the subjects took active measure (jogging and walking) to increase their fitness in preparation for the trip. Despite this, the subsequent development of AMS in some of the members could not be prevented. None of the baseline data showed any correlation with the development of AMS.

During the trek, a daily record of pulse rates enabled the authors to study the effect of altitude and AMS. It is perhaps worthy of note that none of the subjects developed bradycardia at altitude. Even those with AMS tended to have higher pulse rates at altitude over $3100 \mathrm{~m}$ compared to those below this height. It was thus impossible to confirm the findings of comparative bradycardia in AMS shown by Singh et al. (1969).

The exercise test used on the trek, although simple and not standardized, was highly reproducible in an individual. The authors chose to divide the results of the test into those obtained below $3100 \mathrm{~m}$ and 
those above this height for 2 reasons. Firstly, it was expected that the walk itself would improve fitness and therefore the response to exercise. The first 7 days of the trek were all below $3100 \mathrm{~m}$ and it was on the eighth day that the group first exceeded and remained above this altitude. During these 7 days a decrease in resting heart rate, exercise heart rate and recovery time was seen in the group as a whole and would be consistent with an increase in fitness.

The second reason for considering the exercise test in 2 halves is that AMS rarely occurs below $3100 \mathrm{~m}$ and thereafter its frequency increases. It was therefore particularly interesting to observe the changes that occurred with steady ascent above this height. The resting and exercise heart rates increased progressively with altitude above $3100 \mathrm{~m}$.

When the exercise data were reviewed following the trip, there was no noticeable clear pattern of response that indicated an individual's susceptibility to develop AMS. The 5 subjects who had severe AMS and those with minimal symptoms all responded similarly above $3100 \mathrm{~m}$. However, when the data for the first 8 days (those up to the first day above $3100 \mathrm{~m}$ ) were examined, it became apparent that the 5 subjects who developed severe AMS did not show the training effect seen in the group as a whole. On the other hand, the 5 subjects least affected by AMS did show the training effect. This could be explained in 2 possible ways. Either, the 5 subjects who developed AMS were as fit as possible before the trek and therefore would not be expected to improve, or the presence of early, mild AMS compromised their exercise response.

The PEFR during the trek showed little change until the subjects exceeded $3100 \mathrm{~m}$. Thereafter a significant reduction was seen in the group as a whole but did not continue to fall with altitude. Singh et al. (1969) had noted a similar fall in PEFR in subjects with AMS suggesting it was due to pulmonary congestion. Indeed, the change in PEFR was highly significant above $3100 \mathrm{~m}$ in the 5 subjects who developed severe AMS later $(P<0.01)$. The 5 subjects least affected by AMS did not show a significant change as a group. However, the test remained a poor indicator of subsequent AMS since some subjects with minimal symptoms and no signs of pulmonary congestion also had a marked reduction of PEFR above $3100 \mathrm{~m}$.

Vital capacity remained unaltered during the trip until the last 2 days $(4575$ and $5035 \mathrm{~m}$ ) when it fell in the group as a whole but there was no difference between the 5 subjects with AMS and the 5 subjects least affected. The reasons for this fall in VC is not certain, but Rahn and Hammond (1952) noted similar changes in normal subjects at high altitude and attributed it to incipient pulmonary oedema or muscle weakness.

On returning from the trip, the repeat submaximal exercise test showed that the heart rate response to exercise was lower in the group as a whole, demonstrating a training effect (Clausen, 1977) and 'fitness' had improved (Spiro et al., 1974). It was of interest, however, that the 5 subjects who had had severe AMS did not show this improvement whereas the 5 least affected did show the improvement seen in the group as a whole. This is similar to the findings of the exercise test on the trek after the first 7 days. It again suggests that either the subjects with AMS were as 'fit' as possible before the trek, or that AMS had impaired the cardiovascular adjustment to continued arduous exercise. However, the results of this formal exercise test add further validity to the results of the test used on the trek.

In conclusion, the baseline data, exercise and pulmonary function tests on trek were unable to predict the individual susceptibility to developing AMS. However, the group with AMS failed to demonstrate a training effect during or after the trek. Similarly, these 5 subjects clearly demonstrated a fall in PEFR at altitudes above $3100 \mathrm{~m}$. The results suggest that a more formal and controlled exercise test during a trek may predict those subjects likely to develop AMS. However, it should be emphasize that these results are based on a small number of subjects with a wide range of response and furthee studies are necessary to confirm these findings.

\section{Acknowledgments}

We would like to thank Mrs J. Calder who performed the laboratory pulmonary function tests and Mrs W. Davis who typed the manuscript.

\section{References}

Astrand, I. (1960) Aerobic work capacity in men and women with special reference to age. Acta physiologica scandinavica, 49 (Suppl.), 169.

Clausen, J.P. (1977) Effect of physical training on cardiovascular adjustments to exercise in man. Physiological Reviews, 57, 779.

CoTES, J.E. (1972) Response to progressive exercise: a three index test. British Journal of Disease of the Chest, 66, 169.

CoTES, J.E. (1975) Lung Function, 3rd edn, p. 386. Blackwell Scientific Publications, Oxford.

FletCher, R.F. (1962) The measurement of total body fat with skinfold calipers. Clinical Sciences, 22, 333.

FletCher, R.F. (1979) BMRES 1977 expedition: Signs and symptoms. Postgraduate Medical Journal, 55, 461.

Hackett, P.H., RenNie, D. \& Levine, H.D. (1976) The incidence, importance and prophylaxis of acute mountain sickness. Lancet, i, 491.

RAHN, H. \& HAMMOND, D. (1952) Vital capacity at reduced barometric pressure. Journal of Applied Physiology, 4, 715.

Singh, I., Khanna, P.K., Srivastava, M.C., Lal, M., Roy, S.B. \& Subramanyam, C.S.V. (1969) Acute mountain sickness. New England Journal of Medicine, 280, 175.

SPIRo, S.G., JuniPer, E., Bowman, P. \& EDWARDS, R.H.T. (1974) An increasing work rate test for assessing the physiological strain of submaximal exercise. Clinical Science and Molecular Medicine, 46, 191. 